\title{
Testing of solar thermal collectors under transient conditions
}

\author{
Tiago Osório $^{\mathrm{a}, \mathrm{b}, *}$, Maria João Carvalho ${ }^{\mathrm{a}}$ \\ ${ }^{a}$ Laboratório Nacional de Energia e Geologia, Estrada do Paço do Lumiar 22, 1649-038 Lisboa, Portugal

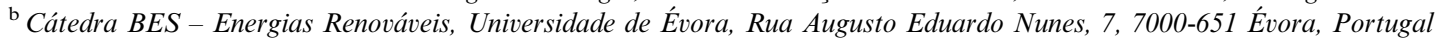

Available online 3 March 2014

\begin{abstract}
The most important standard for collector testing in Europe is the EN 12975:2006 which is applied in all the major laboratories and is the reference for the Solar Keymark certification. Besides the steady-state method, the EN 12975 allows the application of the quasidynamic method performed outdoors in natural conditions with variable radiation and ambient temperature. The available number of days for each test was investigated by analyzing meteorological data series acquired in the Solar Energy Laboratory (LES) in Lisbon since 2008 showing the advantage of the quasi-dynamic test. Both the steady-state and the quasi-dynamic methods were applied to five collectors of different types (two flat plate collectors, one evacuated tube collector with a back reflector and direct flow circulation, one evacuated tube collector with heat pipes, and a CPC collector). The results were compared and a good agreement between the steadystate and the quasi-dynamic test results was observed. Issues concerning the incidence angle modifiers and the effective thermal capacity of the collectors were analyzed in detail, which resulted in the identification of model and test limitations. Suggestions are given to improve the test methodology and the data analysis of quasi-dynamic test.
\end{abstract}

(C) 2014 Elsevier Ltd. All rights reserved.

Keywords: Solar collector testing; Quasi-dynamic model; Steady-state model; EN 12975

\section{Introduction}

Tests on performance and quality of solar collectors have a fairly long history. The current European standards were developed on the basis of the ISO and ASHRAE standards created before 1990. In the most common test methods recommended by ISO 9806-1,3 (ISO, 1994), EN 12975-2 (CEN, 2006) and ASHRAE 93 (ANSI/ASHRAE, 2003) the collector thermal performance is determined under stationary and clear-sky conditions, i.e. steady-state test (SST). The EN 12975-2 also allows testing according to the quasi-dynamic test (QDT) method (clause 6.3), performed under natural conditions (outdoors) with variable

\footnotetext{
* Corresponding author at: Cátedra BES - Energias Renováveis, Universidade de Évora, Rua Augusto Eduardo Nunes, 7, 7000-651 Évora, Portugal. Tel.: +351 266759350 .

E-mail address: tiagoosorio@uevora.pt (T. Osório).
}

radiation and ambient temperature (Fischer et al., 2004). In the past years, this method has been applied to several types of solar collectors, namely, flat plate, CPCs (compound parabolic concentrators) and ETCs (evacuated tubular collectors) (Perers, 1997; Horta et al., 2008; Zambolin and Del Col, 2010). The concentrating collectors are also mentioned in the ASHRAE 93-77, ISO 9806-1 and EN 12975-2 but no specific test methods have been developed within these standards. However the QDT was applied to a parabolic trough with good results (Fischer et al., 2006).

The understanding of the transient behavior of a solar collector is important to know how it will perform during the initial phase of heating, how temperature will vary in days with intermittent clouds, when auxiliary heaters will be needed and is also important to study complex systems that have solar collectors as components, such as solar 